\title{
Multiparametric Microsensors on Lab-on-chip Systems for the Detection of Dissolved Substances
}

\author{
Y. Eminaga ${ }^{1}$, J. Wiest $^{2}$, M. Brischwein ${ }^{1}$, H. Grothe ${ }^{1}$ and B. Wolf ${ }^{1}$ \\ ${ }^{1}$ Heinz Nixdorf-Lehrstuhl für Medizinische Elektronik, Technische Universität München, \\ Theresienstr. 90, 80333 Munich, Germany \\ eminaga@tum.de \\ ${ }^{2}$ cellasys GmbH - R\&D, Karlstr. 96, 80335 Munich, Germany
}

\begin{abstract}
:
A microsensor chip fabricated in silicon technology was developed at the Heinz Nixdorf-Lehrstuhl für Medizinische Elekronik at Technische Universität München. This BioChip contains microsensors for measurement of $\mathrm{pH}$, dissolved oxygen, bioimpedance and temperature. Furthermore it was possible to realize a new sensor for dissolved redox active substances. Using a noble metal electrode (NME) surrounding an ISFET (ion sensitive field effect transistor) $\mathrm{pH}$-sensor it was possible to measure dissolved oxygen concentration indirectly via the resulting change in the $\mathrm{pH}$ value when applying $-700 \mathrm{mV}$ at the NME. The concept of this $\mathrm{O}_{2}$-FET was extended successfully also for measuring other dissolved redox-active substances, using a cyclovoltammetric (CV) scanning mode. With this approach of a so called CV-FET sensor, dissolved substances can be detected according to their specific CV patterns.
\end{abstract}

Key words: Cyclovoltammetry, microsensors, ISFET, CV-FET, pH value, dissolved substances

\section{Introduction}

Electrochemical microsensors are key components for various applications in the field of biology, medicine, pharmacology and environmental analysis. Various detection methods such as amperometry, potentiometry or impedimetry are commonly used. The combination of several electrochemical detection methods enables the detection of new substances as well as the determination of the concentration of known substances more precisely [1]. Those techniques require the development of smart sensors with low cost, low power consumption and ease of use.

In biomedical research, for example, the reaction of cell cultures to drugs or toxic substances can be observed by bioelectronic sensor chips [2]. The biochemical activities of these living cells alter their microenvironment. By measuring changes in $\mathrm{pH}$ value and oxygen content in close vicinity of the cells, the influence of chemical agents on the cell vitality can be determined.

Semiconductor microsensors have the can be manufactured in small dimensions and - at large scale production - with low costs. This allows to integrate different sensor types in close proximity and therefore the combination of different sensor principles. Another advantage is that miniaturized electronic circuits and structures (e.g. memories or amplifiers) could be fabricated along with the sensor on the same wafer [3].

\section{Materials and Methods}

The CV-FET sensor chip, manufactured on a silicon substrate [4] is fixed on a PLCC68compatible printed wire board $(24 \mathrm{~mm} \times 24 \mathrm{~mm})$ and encapsulated to create a culture vessel with a diameter of $6 \mathrm{~mm}$ (see Fig. 1). Beside six ISFET microsensors (including two CV-FETs), an electrode structure for amperometric oxygen measurement, a temperature sensor and an interdigitated electrode structure are included on the chip.

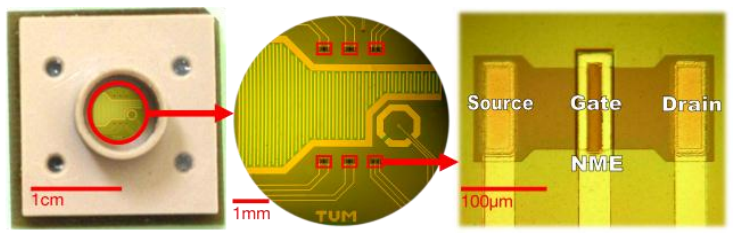

Fig. 1. The sensor chip. Left: Chip in package. Middle: Detail showing the position of six ISFETs. Right: Detail showing an ISFET with NME (CV-FET).

Based on previous developments [5], the CVFET microsensor was developed by combining a voltammetric electrode with an ISFET [6]. 
On an ISFET, the metallic gate contact is replaced by an ion sensitive insulating layer with a surface potential depending on the ion $\left(\mathrm{H}^{+}\right)$concentration. An increasing positive gate potential due to increasing $\mathrm{pH}$ opens the conducting current though the transistor. So, higher $\mathrm{pH}$ values will cause higher gate potentials and corresponding higher currents will flow from source to drain in the transistor.

A single sensor structure combining both the measurement of $\mathrm{pH}$ value and that of dissolved redox couples is realized by an additional ring shaped platinum NME (noble metal electrode) surrounding the ISFETs ion-sensitive gate area.

Importantly, the redox reaction must involve the release or consumption of $\mathrm{H}^{+}$ions. The general chemical redox equation can be written as eq. (1):

$$
X H_{n}+H^{+}+e^{-} \leftrightarrow X H_{n+1}
$$

An example is the oxygen reduction reaction (eq. 2):

$$
\mathrm{O}_{2}+2 \mathrm{H}_{2} \mathrm{O}+2 \mathrm{e}^{-} \rightarrow 4 \mathrm{OH}^{-}
$$

With the resulting CV-FET microsensor (see Fig. 2) the measurement of dissolved oxygen in cell culture media is feasible by applying a fixed cathodic potential at the $\mathrm{NME}$ (vs. a $\mathrm{Ag} / \mathrm{AgCl}$ reference electrode in $3 \mathrm{M}$ potassium chloride solution).

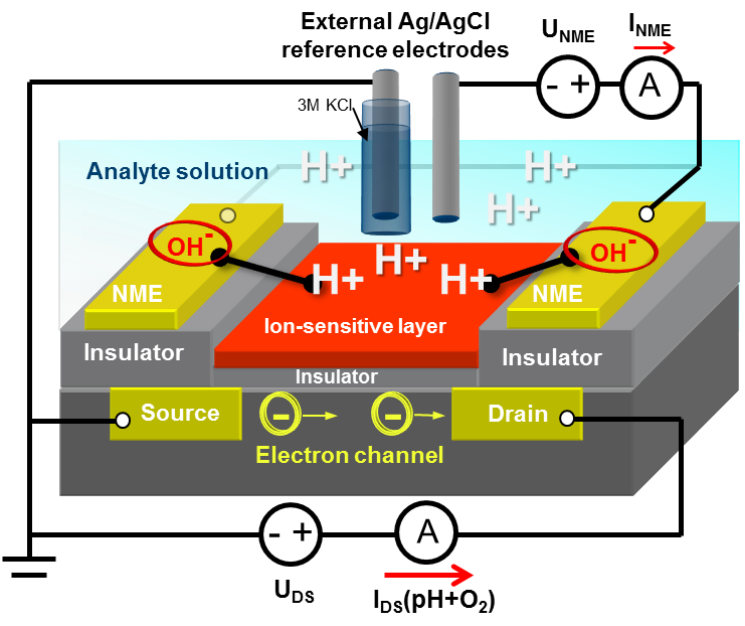

Fig. 2. Dissolved substances can be detected using the CV-FET. Here, oxygen dissolved in phosphate buffered saline (PBS) is reduced to $\mathrm{OH}^{-}$ ions by applying a fixed cathodic $U_{N M E}$ voltage. The local increase of $\mathrm{pH}$ is detected by the ISFET.

When the cathodic NME potential is switched off, the native $\mathrm{pH}$ value of the bulk fluidic media is measured [7].

By applying different NME potentials or potential ramps (cyclovoltammetry) instead of fixed potentials, this concept was extended to detect not only oxygen but also other dissolved substances.

When the cyclovoltammetric potential ramp reaches the oxygen reduction voltage of $-700 \mathrm{mV}$, dissolved oxygen - similar to the fixed potential method - is reduced and this locally shifts the measured $\mathrm{pH}$ value.

In a second experiment the redox couple hydroquinone / quinone $\left(\mathrm{C}_{6} \mathrm{H}_{6} \mathrm{O}_{2} / \mathrm{C}_{6} \mathrm{H}_{4} \mathrm{O}_{2}\right)$ is added to $\mathrm{PBS}$ in equal ratio at different concentrations. The redox reaction catalyzed on the NME is (eq. 3):

$$
\mathrm{C}_{6} \mathrm{H}_{4} \mathrm{O}_{2}+2 \mathrm{e}^{-}+2 \mathrm{H}^{+} \leftrightarrow \mathrm{C}_{6} \mathrm{H}_{6} \mathrm{O}_{2}
$$

\section{Results}

Measurement of PBS solutions with different $\mathrm{pH}$ values showed that - by the CV-FET microsensor - the $\mathrm{pH}$ value can be detected independent from the dissolved oxygen concentration. In the graph in Fig. 3, the detected signals for $\mathrm{pH} 5$ and $\mathrm{pH} 7$ are almost parallel. This is also the case if dissolved oxygen is detected at an $U_{\mathrm{NME}}$ of approximately $-700 \mathrm{mV}$. In general, a higher $\mathrm{pH}$ value causes a higher $I_{D S}$ current.

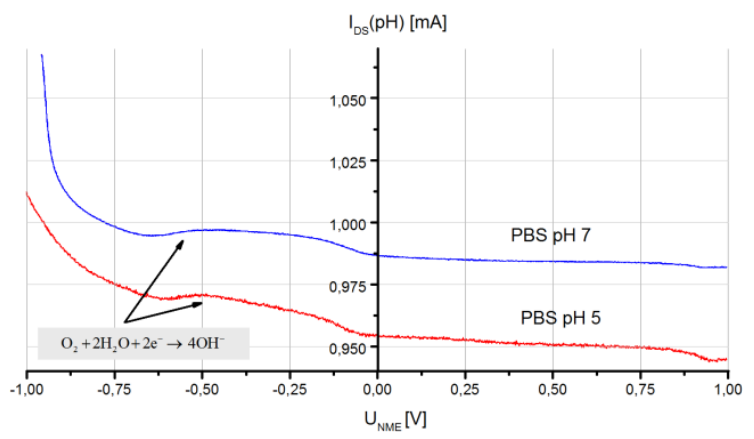

Fig. 3. Graph of measuring different $\mathrm{pH}$ valued PBS with same dissolved oxygen concentration by using CV-FET measurement method

The $\mathrm{pH}$ value shifts at negative $U_{\mathrm{NME}}$ voltages are caused by the reduction of dissolved oxygen as mentioned before according to eq. (2). Since both solutions have the same dissolved oxygen concentration, their shifts in $\mathrm{pH}$ value are also in the same range.

The solution with the hydroquinone / quinone $\left(\mathrm{C}_{6} \mathrm{H}_{6} \mathrm{O}_{2} / \mathrm{C}_{6} \mathrm{H}_{4} \mathrm{O}_{2}\right)$ redox couple shows a similar behavior. At an applied cathodic $U_{\mathrm{NME}}$ voltage (according to eq. (4)) quinone is reduced to hydroquinone. The produced $\mathrm{H}^{+}$ions are the cause of a local increase of the $\mathrm{pH}$ value at the microsensor.

$$
\mathrm{C}_{6} \mathrm{H}_{6} \mathrm{O}_{2} \rightarrow \mathrm{C}_{6} \mathrm{H}_{4} \mathrm{O}_{2}+2 \mathrm{e}^{-}+2 \mathrm{H}^{+}
$$


Similarly but as an anodic reaction, hydroquinone is oxidized to quinine. Here, a local drop of the $\mathrm{pH}$ value occurs (see Fig. 4). The shifts in the $\mathrm{pH}$ value are proportional to the dissolved concentration of the redox couple.

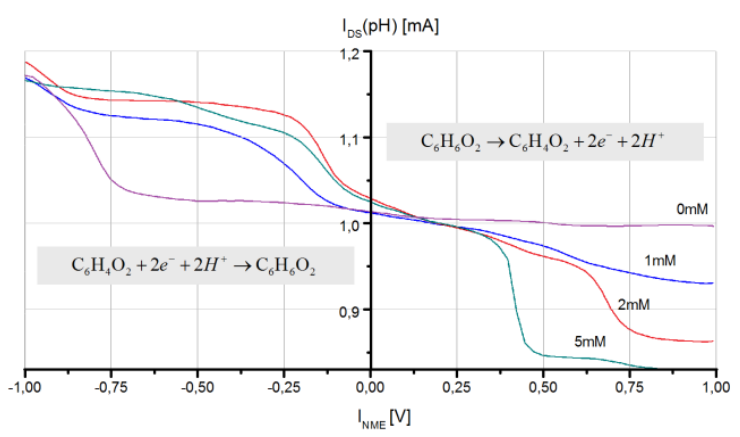

Fig. 4. Graph of measuring different concentrations of hydroquinone / quinone using CV-FET measurement method

In Fig. 5 the plots of the ISFET current vs. the anodic NME voltage are normalized to the plot obtained in a hydroquinone / quinone free solution. It is shown that the microsensor can detect different concentrations of the hydroquinone / quinine couple at an $U_{\mathrm{NME}}>$ $400 \mathrm{mV}$.

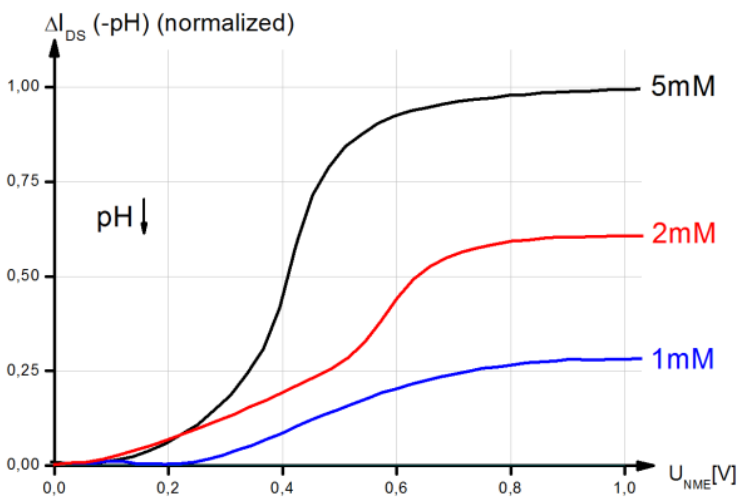

Fig. 5. Graph of normalized ISFET currents Different concentrations of hydroquinone / quinone in $P B S$ are detected using a CV-FET microsensor.

\section{Conclusion and Outlook}

With the so called CV-FET a simultaneous measurement of $\mathrm{pH}$ and dissolved oxygen is possible with the same sensor structure [8]. Beyond this, other redox couples with an involvement of $\mathrm{H}^{+}$(or $\mathrm{OH}^{-}$) ions such as hydroquinone / quinone can be detected by scanning the NME potential.

Further research is needed to identify more significant CV patterns of other redox-active substances, which will allow linking these characteristic patterns to their corresponding dissolved substances.

\section{Acknowledgements}

The authors would like to express their thanks to cellasys $\mathrm{GmbH}$ for technological support and the Heinz Nixdorf Stiftung for funding this project.

\section{References}

[1] B. Wolf, M. Brischwein, A. Otto, H. Grothe, Chip statt Maus: Zur Bedeutung multiparametrischer biohybrider Bauelemente in Toxikologie und Pharmascreening; Technisches Messen 70, 553556 (2003); doi: 10.1524/teme.70.12.553.20256

[2] B. Wolf, M. Kraus, M. Brischwein, R. Ehret, W. Baumann, M. Lehmann, Biofunctional hybrid structures - cell-silicon hybrids for applications in biomedicine and bioinformatics;

Bioelectrochemistry and Bioenergetics 46, 215225 (1998); doi: 10.1016/S0302-4598(98)00169$\mathrm{X}$

[3] J. Wiest, T. Stadthagen, M. Schmidhuber, M. Brischwein, J. Ressler, U. Raeder, H. Grothe, A. Melzer, B. Wolf, Intelligent Mobile Lab for Metabolics in Environmental Monitoring, Analytical Letters 39, 1759-1771 (2006); doi: 10.1080/000327 10600714089

[4] M. Brischwein, H. Grothe, A.M. Otto, C. Stepper, E. Motrescu, T. Weyh, B.Wolf: Living Cells on Chip: Bioanalytical Applications. in: Ultrathin Electrochemical Chemo- and Biosensors. Mirsky, V.M. (ed.), 159-180. Springer-Verlag, Berlin 2004

[5] M. Lehmann, W. Baumann, M. Brischwein, H.-J. Gahle, I. Freund, R. Ehret, S. Drechsler, H. Palzer, M. Kleintges, U. Sieben, B. Wolf, Simultaneous measurement of cellular respiration and acidification with a single CMOS ISFET; Biosensors \& Bioelectronics 16, 195-203 (2001); doi: 10.1016/S0956-5663(01)00123-3

[6] P. Bergveld, Thirty years of ISFETOLOGY What happened in the past 30 years and what may happen in the next 30 years; Sensors and Actuators B Chemical 88, 1-20 (2003); doi: 10.1016/S0925-4005(02)00301-5

[7] Y. Eminaga, J. Wiest, M. Brischwein, H. Grothe, B. Wolf, Silizium-Basierter Multiparametrischer Biohybrider Mikrosensoren; MikroSystemTechnik KONGRESS 2009, 112(2009)

[8] B. Wolf, M. Brischwein, V. Lob, J. Ressler, J. Wiest, Cellular Signalling: Aspects for Tumor Diagnosis and Therapy; Biomedizinische Technik 52, 164-168(2007); doi: 10.1515/BMT.2007.030 